\title{
Estudo de áreas suscetíveis a movimentos de massa na Rodovia RS 486, Rota do Sol
}

\author{
Michele Monguilhott ${ }^{(1)}$, Dejanira Luderitz Saldanha( ${ }^{(1)}$, Elódio Sebem ${ }^{(2)}$, Sergio Florêncio de Souza(1)
}

\begin{abstract}
(1) Universidade Federal do Rio Grande do Sul (UFRGS), Av. Bento Gonçalves, 9500, Prédio 43.136, sala 103, Porto Alegre, RS. michelegads@ yahoo.com.br; 00001142@ufrgs.br; sergio.florencio@ufrgs.br; (2) Universidade Federal de Santa Maria (UFSM), Av. Roraima, 1.000, Prédio 70, Bairro Camobi, Santa Maria, RS. elodiosebem@gmail.com
\end{abstract}

\begin{abstract}
Resumo - O desenvolvimento de novos aglomerados urbanos, bem como a necessidade de escoamento da produção de bens e a maior circulação de pessoas, exige a intervenção do homem em espaços antes não habitados ou preservados da interferência humana. Obras de infraestrutura têm efeito direto sobre os ecossistemas e a RS 486 provoca, além do impacto visual na paisagem, uma forte fragmentação no bioma Mata Atlântica. A retirada da vegetação no entorno da rodovia pode facilitar a ocorrência de desastres naturais relacionados com mudanças na geomorfologia e nos processos intempéricos, resultando em erosão e acomodação do solo. Com o objetivo de mapear áreas vulneráveis e suscetíveis a movimentos de massa na sub-bacia hidrográfica do Rio Três Forquilhas, ao longo da rodovia RS 486, foram empregadas técnicas de geoprocessamento e sensoriamento remoto para a elaboração de mapas de vulnerabilidade ambiental a partir do emprego das variáveis como o uso do solo, geomorfologia, geologia, modelo digital de elevação (MDE), declividade e índices de vegetação (NDVI), aplicando-se o método de análise hierárquica de apoio à decisão conhecido como análise hierárquica de decisão (AHD). Os mapas resultantes atendem ao propósito de definir áreas prioritárias para a atuação da Defesa Civil do Estado do Rio Grande do Sul.
\end{abstract}

Termos para indexação - Vulnerabilidade, movimento de massa, bioma, rodovias, geoprocessamento, sensoriamento remoto.

\section{Study of areas susceptible to mass movements in the Highway RS 486, Route of the Sun}

\begin{abstract}
The development of new urban areas and the necessity of disposing of goods production and increased movement of people requires the intervention of man in areas previously not inhabited or preserved of the human interference. Infrastructural work sites have direct effects on ecosystems and RS/486 causes, beyond the visual impact on the landscape, a strong fragmentation in Atlantic forest. The removal of vegetation around the highway can facilitate the occurrence of natural disasters related to changes in geomorphology and weathering processes may result erosion and soil accommodation. To study the vulnerability and susceptibility the mass movements of the sub-watershed Três Forquilhas river along the highway RS 486 were employed techniques of GIS and remote sensing to produce maps of environmental vulnerability from employment of such variables as land use, geomorphology, geology, digital elevation model (DEM), slope and normalized digital vegetation index (NDVI) by applying analytic hierarchy process method (AHP) to support decision. The resulting maps matchie the purpose of defining priority areas for action of the Rio Grande do Sul State Civil Defense.
\end{abstract}

Index terms - Vulnerability, mass movements, biome, roads, geoprocessing, remote sensing.

\section{Introdução}

O desenvolvimento de novos aglomerados urbanos bem como a necessidade de escoamento da produção de bens e a maior circulação de pessoas exige a implantação de obras de infraestrutura que podem impactar os ecossistemas onde se inserem.
Esses impactos são constantemente estudados por pesquisadores de diversas áreas de conhecimento (geólogos, geógrafos, engenheiros civis e biólogos), buscando minimizar os efeitos destas obras sobre os ecossistemas. A legislação ambiental busca minimizar esses efeitos impondo a obrigatoriedade de estudos de impacto ambiental (EIA). 
Deslizamentos são fenômenos com várias formas e processos de movimentos de massa. Dentre essas formas, destacam-se os deslizamentos nas encostas, em função da sua interferência grande e persistente com as atividades do homem, da extrema variância de sua escala, da complexidade de causas e mecanismos, além da variabilidade de materiais envolvidos (Fernandes \& Amaral, 996).

A identificação das áreas críticas está associada ao risco de deslizamento classificado por Alberton (2004) como sendo atual "quando instalado em áreas já ocupadas, ou potencial, quando envolvem a susceptibilidade de ocorrência em áreas ainda desocupadas".

As mudanças ocorridas no ambiente geram a necessidade do constante monitoramento que, por sua vez, mantenha as informações atualizadas. $\mathrm{O}$ sensoriamento remoto favorece o monitoramento dessas informações através do uso de imagens multiespectrais, as quais estão periodicamente sendo adquiridas por sensores orbitais. Desta forma, a facilidade para o mapeamento e visualização de informações, após classificação e análise, auxilia na tomada de decisão e minimiza os possíveis riscos e danos ambientais locais.

O presente trabalho monitorou as áreas suscetíveis a movimentos de massa na sub-bacia hidrográfica do Rio Três Forquilhas, local de inserção da Rodovia RS 486 , chamada Rota do Sol.

\section{Material e métodos}

O clima da região, segundo classificação climática de Köppen, caracteriza-se como Cfb, subtropical, com verões brandos e invernos mais acentuados. Na região dominam os modelados esculpidos em depósitos de origem continental, com predomínio da vegetação pioneira, alterada pela ação antrópica dominando os planossolos, gleissolos e areias quartzosas. Integra duas unidades geomorfológicas: a Planície Lagunar e a Planície Alúvio-Coluvionar. Na área de estudo predominam os solos litólicos eutróficos (RE) associados com brunizem avermelhado (BV), areias quartzosas distróficas (AQD) e areias quartzosas hidromórficas húmicas álicas (HAQHa) (IBGE, 1986).

A área se distingue segundo subdivisão proposta por Lisboa (1996), por sua estrutura geológica inserida na Unidade Hidrogeológica da Fachada Atlântica, aplainada por lineamentos de médio e pequeno porte que abastecem as fraturas em profundidade. Estas apresentam descontinuidades nas estruturas, o que influencia a estabilidade dos taludes, classificadas por Nummer (2003), em sua origem tectônica, como juntas e falhas nas direções NW-SE, NE-SW, E-W e N-S e as de origem não tectônicas como fluxo, fraturas de resfriamento e juntas de alívio, com vertentes orientadas na direção SW-NE, com declividades que variam de $5^{\circ}$ a $12^{\circ}$ e vertentes predominando no sentido noroeste entre $35^{\circ}$ e $45^{\circ}$.

Para a elaboração de mapas de vulnerabilidade ambiental, utilizou-se o método desenvolvido por Saaty (1977), de análise hierárquica de apoio à decisão Analytic Hierarchy Process (AHP), geoprocessamento e sensoriamento remoto, sendo que os mesmos podem servir para a determinação de áreas prioritárias e auxiliar na atuação da Defesa Civil do Estado do Rio Grande do Sul. Mapas desse tipo vêm sendo usados desde a década de 1970 e são uma importante ferramenta para seleção de ambientes mais frágeis e, portanto, com maior necessidade de proteção.

\section{Área de estudo}

A Rodovia RS 486 - Rota do Sol (Figura 1), antes denominada RS 025, faz a integração da BR 101 na zona litorânea, junto à cidade de Terra de Areia, à localidade de Tainhas, no Planalto Meridional, junto à Rodovia RS 020, e une as cidades de São Francisco de Paula à Cambará do Sul. Constitui-se em uma rota de grande importância econômica e turística no Rio Grande do Sul, uma vez que permite a ligação da região serrana ao litoral gaúcho.

Está situada na região nordeste do Rio Grande do Sul e sua extensão é de $53.458 \mathrm{~km}$, caracterizada principalmente por várias intervenções construídas e adotadas como medidas mitigadoras. Os viadutos e túneis da RS 486, sem dúvida, são objetos que provocam um forte impacto visual mais caracterizado, segundo o Relatório de Impacto Ambiental (Rima) da fase de operação da rodovia, como um impacto positivo. Explica-se no Rima que estas "obras de arte" marcam com personalidade a presença do homem no meio ambiente e que são construídas para adequar a rodovia à topografia, onde as pontes e viadutos (Figura 2), muitas vezes, evitam o desmatamento, cortes ou grandes aterros, preservando também os cursos d'água. 

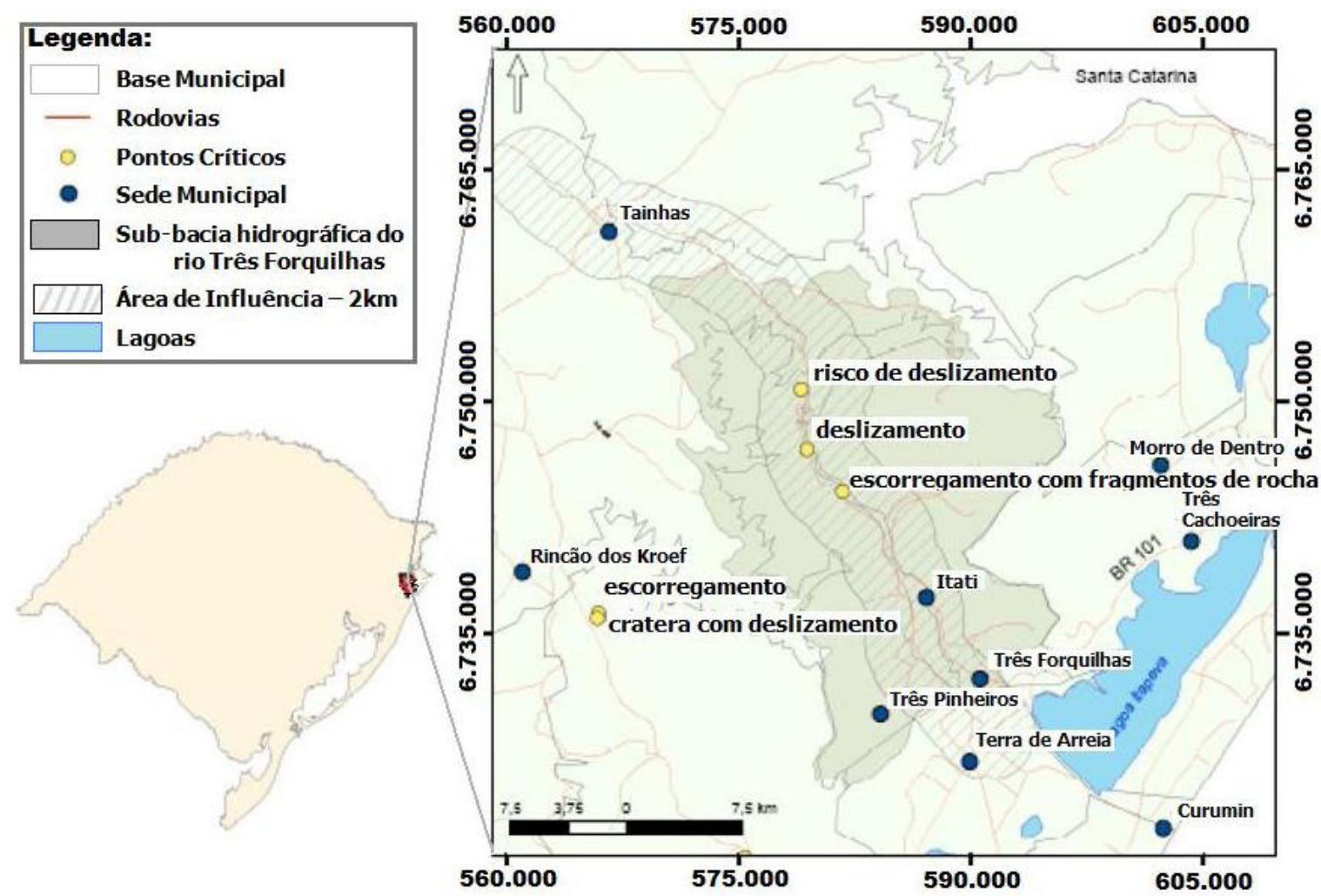

Figura 1. Localização da Sub-bacia hidrográfica do Rio Três Forquilhas, com destaque para a área de influência definida para a RS 486 .

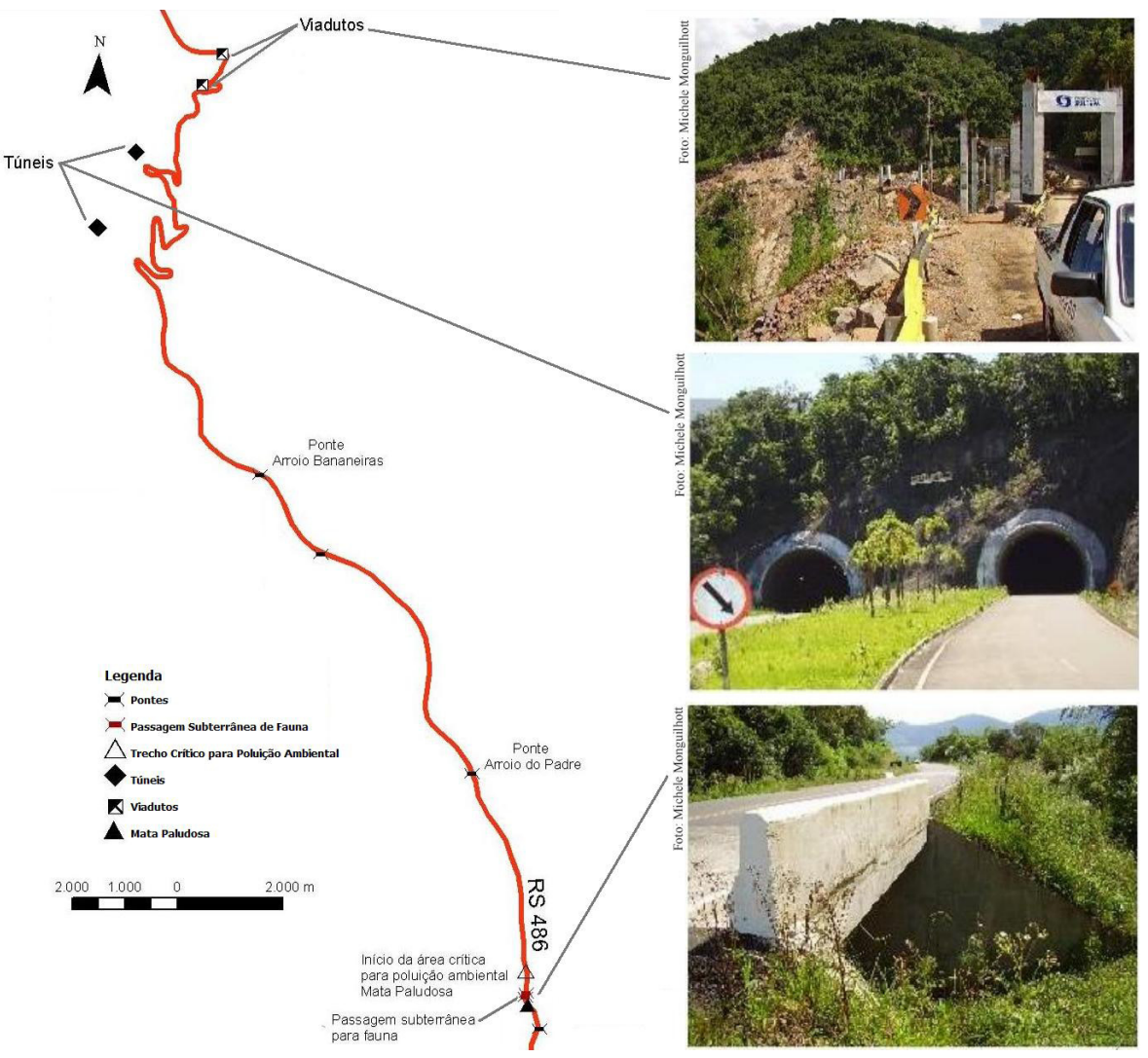

Figura 2. Localização das principais "obras de arte" da rodovia RS 486 Rota do Sol. 
As "obras de arte" construídas para a Rota do Sol, mesmo que para mitigar o impacto ambiental inicial, causam um forte impacto visual, cortando e modificando a paisagem da rodovia. A grande quantidade de aterros e cortes na rodovia em toda sua extensão proporciona a intensificação dos fenômenos erosivos que são facilitados pela abertura de taludes. Nestes taludes, a inclinação e altura dos cortes, a sensibilidade do solo e a intensidade de chuvas intensificam a ocorrência da erosão. Neste aspecto, a proteção vegetal da superfície dos taludes e as obras de contenção atenuam os processos erosivos instalados.

Como material de suporte para a integração das informações, utilizaram-se os mapas geológicos, geomorfológicos e de solos (Tabela 1); a reclassificação da base e integração das variáveis resultou no mapa de aspectos fisiográficos da área ou unidade ecodinâmica como proposto por Ross (1991). Estes aspectos foram utilizados como um dos critérios para a aplicação da análise hierárquica de decisão (AHD).
Como limite para o processamento dos dados e análise espacial, foi definida a Sub-bacia hidrográfica do Rio Três Forquilhas e, através de um buffer por análise de proximidade, com o uso da ferramenta $3 D$ Analyst do programa ArcGIS (ESRI), uma área de influência de dois quilômetros da rodovia RS 486.

O referencial cartográfico definido para o trabalho foi o sistema de projeção universal transversa de mercator (UTM), Datum WGS84 - Fuso 22S. Os arquivos foram gerados no formato shapefile, em programas de geoprocessamento (ArcGIS), e armazenados no banco de dados do projeto. Os mapas temáticos foram gerados na escala 1:100.000 e as bases compiladas de outros órgãos foram convertidas para a projeção e datum adotadas no projeto.

O mapa de declividade para a sub-bacia resultou da interpolação dos dados pelo método da krigagem correspondente ao modelo digital de elevação (MDE)/ SRTM.

Tabela 1. Bases cartográficas utilizadas.

\begin{tabular}{|c|c|}
\hline Informação & Origem da informação \\
\hline Divisão territorial & Existente em formato digital - IBGE (2001) \\
\hline Geologia & $\begin{array}{l}\text { Carta Geológica em escala 1:250.000 - CPRM } \\
\text { Existente em formato analógico: Mapa Geológico Regional em escala 1:100.000-IBGE (1986). } \\
\text { Convertido para o formato vetorial através de vetorização em tela e apresentado em } \\
\text { escala 1:250.000. }\end{array}$ \\
\hline Geomorfologia & $\begin{array}{l}\text { Existente em formato analógico: Mapa Geomorfológico Regional em escala 1:100.000-IBGE(1986). } \\
\text { Convertido para o formato vetorial através de vetorização em tela. }\end{array}$ \\
\hline Solos & $\begin{array}{l}\text { Existente em formato analógico: Mapa de Solos Regional em escala 1:100.000 - IBGE (1986). } \\
\text { Convertido para o formato vetorial através de vetorização em tela. }\end{array}$ \\
\hline Bacia Hidrográfica do Rio Três Forquilhas & Existente em formato digital na escala 1:100.000 - Lageo/UFRGS \\
\hline Fragmento $2 \mathrm{~km}$ da RS 486 & Elaborado a partir de buffer da estrada RS 486 - Rota do Sol \\
\hline Pontos levantados em campo & $\begin{array}{l}\text { Transferidos do GPS com o uso do programa TrackMaker e convertidos em shapefile } \\
\text { para uso no ArcGis }\end{array}$ \\
\hline $\begin{array}{l}\text { Vegetação } \\
\text { Unidades de Conservação } \\
\text { Áreas indígenas }\end{array}$ & $\begin{array}{l}\text { Existente em formato digital em escala 1:250.000 - MMA 2007, coordenadas geográficas- } \\
\text { Datum SAD } 69\end{array}$ \\
\hline $\begin{array}{l}\text { Hipsometria } \\
\text { Recursos hídricos }\end{array}$ & $\begin{array}{l}\text { Existente em formato digital - FEPAM (2004), em escala 1:250.000, coordenadas } \\
\text { geográficas-Datum SAD } 69\end{array}$ \\
\hline Estrada RS 486 & $\begin{array}{l}\text { Elaborada a partir de navegação em campo e transferida do GPS com o uso do programa } \\
\text { TrackMaker, após conversão para formato shapefile (shp). }\end{array}$ \\
\hline MDE & $\begin{array}{l}\text { Elaborada a partir de arquivo vetorial de Curvas de Nível, disponível em CD-ROM, em escala } \\
\text { 1:250.000, da Base Cartográfica do Rio Grande do Sul, preparada para SIG pela FEPAM (2004) }\end{array}$ \\
\hline Declividade & $\begin{array}{l}\text { Elaborada a partir de MNT, gerado através de arquivo vetorial de Curvas de Nível } \\
\text { disponível em CD ROM em escala 1:250.000, da Base Cartográfica do Rio Grande do } \\
\text { Sul, preparada para SIG pela FEPAM (2004) }\end{array}$ \\
\hline
\end{tabular}


Para minimizar a variabilidade causada por fatores externos, e no sentido de proporcionar melhor interpretação da cobertura vegetal da sub-bacia, normalizou-se a imagem SPOT 5, do sensor HRG, obtendo-se o índice NDVI, através da seguinte operação aritmética resultando na imagem normalizada:

$\mathrm{NDVI}=\mathrm{B} 3-\mathrm{B} 2 / \mathrm{B} 3+\mathrm{B} 2 * 256$, onde para a determinação do B3 foi utilizada a Banda HRG3 e para o B2 foi utilizada a Banda HRG2. A média resultante da imagem normalizada demonstra que grande parte da cena apresenta densidade média de áreas florestadas. $\mathrm{O}$ NDVI é descrito por Rouse et al. (1973).

Para a determinação dos pontos de instabilidades dos taludes da RS 486, foram inseridas na análise variáveis climáticas com ênfase no regime pluviométrico regional; o substrato rochoso, com ênfase nos principais tipos de rochas e principais tipos de solo e na estrutura geológica (fraturas); a geomorfologia com ênfase no perfil da encosta; uso e ocupação do solo e ênfase na cobertura vegetal, por ser um fator de proteção do solo.

\section{Resultados e discussão}

A região abrangida pela sub-bacia hidrográfica do Rio Três Forquilhas tem relevo escarpado a montanhoso, amplitude topográfica alta, com cotas variando entre 960 m a 100 m (IBGE, 1986). Apresenta vales com profundidades muito acentuadas, maiores de $300 \mathrm{~m} \mathrm{e}$ declividade das vertentes muito fortes a extremamente fortes $\left(30^{\circ}\right.$ a $\left.45^{\circ}\right)$, alta densidade de drenagem e instabilidade geomorfológica.

Está inserida em um ambiente de relevos contrastantes, tendo uma amplitude de $1.080 \mathrm{~m}$, pois abrange desde cotas ao nível do mar até o alto da Serra Geral. Com uma área de $510,60 \mathrm{~km}^{2}$ a sub-bacia facilitou a análise para o processamento e geração dos planos de informações como o MDE, orientação das vertentes (aspecto) e aspectos fisiográficos.

As condições de instabilidade mais representativas nesta região são facilitadas pela ocorrência de tálus e rampas de colúvio (IBGE, 1986). A cobertura vegetal é uma importante variável para a determinação de áreas vulneráveis a movimentos de massa (Figura 3). Sua distribuição tem grande importância nas áreas planas e de média encosta; enquanto nas áreas com declividade alta, a vegetação de grande porte passa a ser potencializadora dos movimentos de massa, pois, com a incidência dos eventos meteorológicos extremos e o solo residual de pouca profundidade, sobrecarrega a camada superficial do substrato rochoso, intensificando os deslizamentos e escorregamentos de massa nas áreas mais íngremes, de acordo com Varnes (1978). Para este autor, nas demais áreas, a cobertura vegetal é uma variável que minimiza a ação erosiva.

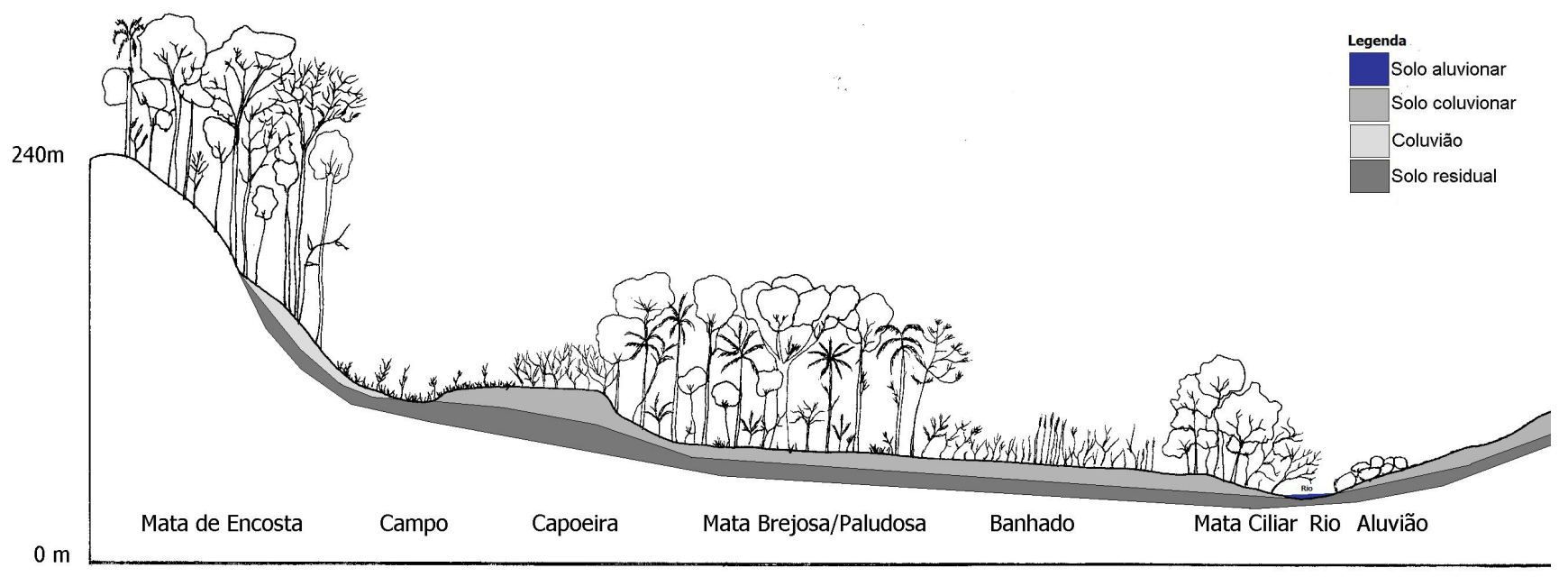

Fonte: Desenho modificado de HAR Eng. e Meio Ambiente Ltda. "Perfil esquemático dos ambientes fitofisiográficos" sem escala, Elaborado pela Desenhista Ruth Coitinho Pinto - Depto. de Geodésia/UFRGS

Figura 3. Perfil esquemático dos ambientes fitofisiográficos do trecho da Mata Paludosa na Sub-bacia hidrográfica do Rio Três Forquilhas. 
Esta constatação é confirmada quando a imagem NDVI é integrada à variável declividade, resultando nas áreas potencializadoras, nas quais se observa a possível relação entre os pontos de deslizamentos confirmados em campo, o tipo de cobertura vegetal de grande porte e a relação entre as cotas, conforme sugerido por Varnes (1978).

Não foi possível confirmar a relação da cobertura vegetal de grande porte como potencializadora dos movimentos de massa nas áreas de encosta da subbacia. Para isto, seria necessário um estudo pontual e acompanhamento periódico da cobertura vegetal instalada em áreas sujeitas a deslizamentos, para determinar esta relação.

O mesmo autor classifica geomorfologicamente os movimentos de talude estabelecendo uma ligação entre a geologia e os movimentos de massa. Dias et al. (1999) comprovam esta relação quando acrescentam que, pela estratigrafia vulcânica da formação Serra Geral no planalto Meridional, no vale do Rio Três Forquilhas, os movimentos de massa se originam na parte superior da escarpa, onde ocorreram os derrames ácidos, associados a episódios de chuvas intensas. Os autores destacam, ainda, que no topo da escarpa também ocorrem quedas, rolamentos e deslizamentos de grandes blocos de rocha, não intemperizados, que podem ser encontrados nas encostas e nos talvegues do vale do Rio Três Forquilhas.

Os movimentos de massa ocorridos na área de estudo são considerados pequenos a grandes e comuns nas encostas dos vales da escarpa do planalto Meridional (Dias et al., 1999). Para estes autores, tais movimentos ameaçam destruir vidas, casas, bem como aumentam os custos de construção e manutenção das estradas. Além disso, os referidos autores classificam estes movimentos como do tipo fluxo de detritos, originados na parte superior da escarpa, durante ou logo após episódios de chuvas torrenciais.

Estes movimentos têm forma erosiva de cicatrizes lineares, desenvolvidas desde o topo até o talvegue dos vales, onde deixam depósitos recentes, não intemperizados, em forma de leque e de material em que predominam blocos e seixos angulares, observados em detalhe na Figura 4.

Foram registrados, nos meses de novembro de 2006 e março de 2007, movimentos de massa recorrentes relacionados com fortes precipitações, bem acima das médias normais para os respectivos meses, causando danos e a interrupção do tráfego na Rodovia RS 486 Rota do Sol.
No triênio 2006-2008 observa-se que os níveis de precipitação não atingiram os valores máximos da normal climatológica da região para os municípios de Três Forquilhas e Terra de Areia. Vale destacar, no entanto, o pico de precipitação ocorrido em março de 2007. Este registro reforça a fragilidade da região de estudo em períodos de forte precipitação, onde há associação entre o solo e a rocha subjacente, e as áreas de alta declividade e a cobertura vegetal de grande porte favorecem a ocorrência dos movimentos de massa, encontrando-se na área de estudo cicatrizes provocadas por deslizamentos (Tabela 2, Figura 1).

Tabela 2. Cicatrizes de deslizamentos na Rodovia RS 486 - Rota do Sol (registros em Novembro de 2006 e Março de 2007).

\begin{tabular}{|c|c|c|c|}
\hline \multicolumn{4}{|c|}{ Novembro/2006 } \\
\hline Ponto & Latitude & Longitude & Cicatrizes \\
\hline Ponto1 & $-29^{\circ} 30,01180^{\prime}$ & $-50^{\circ} 19,19290^{\prime}$ & Deslizamento \\
\hline Ponto2 & $-29^{\circ} 22,14111^{\prime}$ & $-50^{\circ} 11,15891^{\prime}$ & Deslizamento \\
\hline Ponto3 & $-29^{\circ} 22,76470^{\prime}$ & $-50^{\circ} 11,48901^{\prime}$ & Deslizamento \\
\hline Ponto4 & $-29^{\circ} 22,69486^{\prime}$ & $-50^{\circ} 10,82472$ & Deslizamento \\
\hline Ponto5 & $-29^{\circ} 21,48725^{\prime}$ & $-50^{\circ} 10,62551^{\prime}$ & Deslizamento \\
\hline Ponto6 & $-29^{\circ} 21,52329^{\prime}$ & $-50^{\circ} 10,66831^{\prime}$ & Deslizamento \\
\hline Ponto7 & $-29^{\circ} 21,59571^{\prime}$ & $-50^{\circ} 10,72109^{\prime}$ & Deslizamento \\
\hline Ponto8 & $-29^{\circ} 21,74634^{\prime}$ & $-50^{\circ} 10,82151^{\prime}$ & Deslizamento \\
\hline Ponto9 & $-29^{\circ} 21,95812^{\prime}$ & $-50^{\circ} 10,80831^{\prime}$ & Deslizamento \\
\hline Ponto10 & $-29^{\circ} 22,01767^{\prime}$ & $-50^{\circ} 10,81990^{\prime}$ & Deslizamento \\
\hline \multicolumn{4}{|c|}{ Março/2007 } \\
\hline Ponto & Latitude & Longitude & Cicatrizes \\
\hline Ponto1 & $-29^{\circ} 25,70885^{\prime}$ & $-50^{\circ} 09,45861^{\prime}$ & Deslizamento \\
\hline Ponto2 & $-29^{\circ} 24,23983$ & $-50^{\circ} 10,90516^{\prime}$ & Deslizamento \\
\hline Ponto3 & $-29^{\circ} 22,14111^{\prime}$ & $-50^{\circ} 11,15891^{\prime}$ & Deslizamento \\
\hline Ponto4 & $-29^{\circ} 30,01180^{\prime}$ & $-50^{\circ} 19,19290^{\prime}$ & Deslizamento \\
\hline Ponto5 & $-29^{\circ} 30,19575^{\prime}$ & $-50^{\circ} 19,22686^{\prime}$ & Deslizamento \\
\hline Ponto6 & $-29^{\circ} 38,53378^{\prime}$ & $-50^{\circ} 13,27449^{\prime}$ & Deslizamento \\
\hline Ponto7 & $-29^{\circ} 34,02982^{\prime}$ & $-50^{\circ} 02,93072^{\prime}$ & Deslizamento \\
\hline
\end{tabular}

Os vales que modelam a paisagem na área estudada tem perfil em U que, segundo Christofoletti (1981), são “[...] elaborados por uma sucessão de fases fluviais e glaciárias, principalmente em rochas resistentes. $\mathrm{O}$ fundo do vale geralmente é amplo e plano, possuindo bacias fechadas". Corrobora-se a proposta de Nummer (2003) de que os movimentos de massa nesses vales se desenvolvem mesmo em áreas florestadas, pois os mecanismos causadores do fenômeno envolvem as mais diversas variáveis, incluindo intemperismo e, principalmente, a geologia da área (litologia e estrutura 
de rochas), confirmando a continuidade e a recorrência dos movimentos de massa atuais, como sugerido também por Gomes (1976).

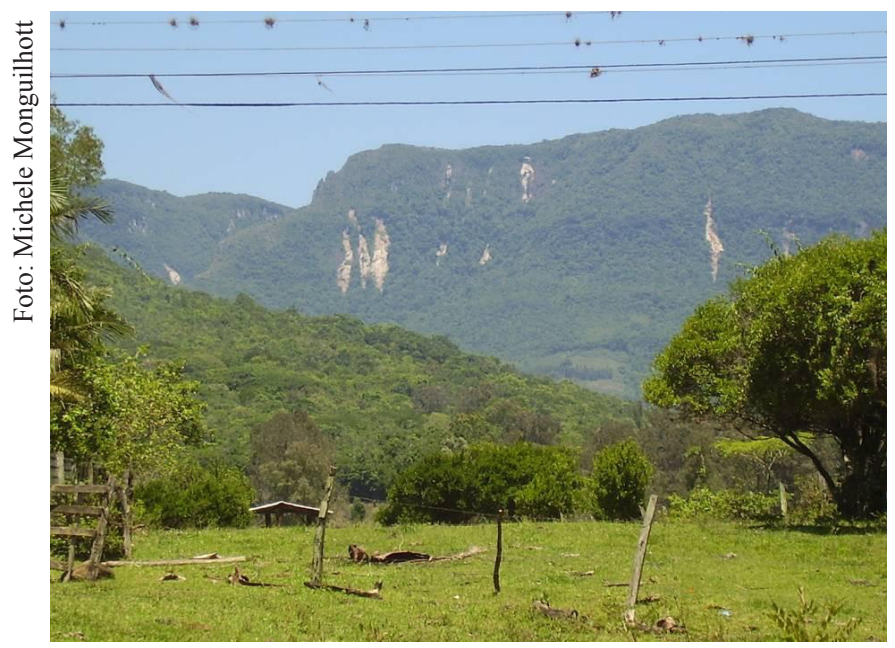

Figura 4. Cicatrizes encontradas na região provocadas por movimentos de massa, Maquine, RS, novembro de 2007

Nota-se que a área de estudo abrange uma região com alto grau de fragilidade associado ao relevo e à litologia (Figura 5) que, embora protegida pela cobertura vegetal, não impede a erosão favorecida pela declividade do terreno.

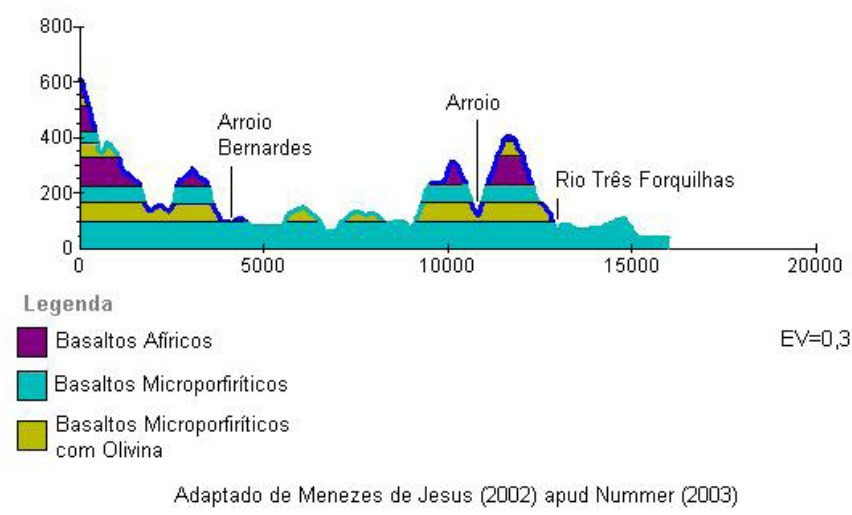

Figura 5. Perfil dos tipos de rochas e modelado dos vales fluviais da área de estudo.

Os pontos críticos de deslizamentos da área de estudo se concentram no domínio geomorfológico da Serra Geral. Constatou-se a existência de uma forte correlação entre os deslizamentos e áreas com fraco grau de proteção, como sugerido por Ross (1991), confirmando a fragilidade da paisagem em associação com suas classes de uso do solo. Na Tabela 3 estão discriminados os graus de proteção, segundo o tipo de cobertura vegetal e uso do solo, propostos por Ross (1991).

Tabela 3. Graus de proteção dados ao solo pela cobertura vegetal face à ação das águas pluviais.

\begin{tabular}{|c|c|}
\hline $\begin{array}{l}\text { Graus de } \\
\text { proteção }\end{array}$ & Tipos de cobertura vegetal/uso do solo \\
\hline $\begin{array}{l}\text { Forte } \\
\text { (1) }\end{array}$ & $\begin{array}{l}\text { - florestas naturais (Floresta Ombrófila) } \\
\text { - florestas cultivadas com diversidade de espécies } \\
\text { e vários estratos (mata de encosta) }\end{array}$ \\
\hline $\begin{array}{l}\text { Média } \\
(2)\end{array}$ & $\begin{array}{l}\text { - formações arbustivas densas de origem secundária } \\
\text { (capoeira) } \\
\text { - formações naturais ou cultivadas de gramíneas } \\
\text { (estepe) }\end{array}$ \\
\hline $\begin{array}{c}\text { Fraca } \\
(3)\end{array}$ & $\begin{array}{l}\text { - áreas desmatadas recentes (abertura do talude } \\
\text { para construção da estrada) } \\
\text { - agricultura de ciclo curto (área de ocupação } \\
\text { agrícola e solo agrícola) }\end{array}$ \\
\hline
\end{tabular}

Mesmo antes da aplicação da análise hierárquica de tomada de decisão integrando as demais variáveis, observou-se uma forte relação das ocorrências de deslizamentos com a fragilidade do sistema, mostrando que essas ocorrências estão relacionadas a eventos naturais, facilitados pela ação antrópica.

Para o estabelecimento da contribuição de cada variável envolvida na análise e sua relação com as áreas suscetíveis a movimentos de massa para a Sub-bacia hidrográfica do Rio Três Forquilhas na área de influência da rodovia RS 486 - Rota do Sol, utilizou-se critérios sugeridos por Ross (1991), submetendo as variáveis ao Processo Analítico Hierárquico (AHP) (ESRI, 2007).

Todos os critérios/fatores (Tabela 3) considerados relevantes para a decisão foram comparados em pares em uma matriz que é uma medida relativa que expressa a preferência entre os fatores processados.

As classes de instabilidade foram descritas através de percentuais padrões calculados pela AHP referentes às informações de índice de vegetação, uso do solo e aspectos fisiográficos (unidade ecodinâmica - Solos, Geologia e Geomorfologia) da sub-bacia. Na Tabela 4 pode-se visualizar, além dos critérios, os pesos que resultaram na razão de consistência de 0,0772 , onde o NDVI não conseguiu alcançar este valor.

Como propõe Carvalho \& Roedel (2004), os pesos atribuídos aos condicionantes e suas classes podem ser alterados a qualquer momento. No entanto, se a razão de consistência for superior a 0,1 , executa-se novamente o processo AHP para que o mapa final seja atualizado 
após cada modificação de critérios e pesos. Isto foi feito para que o NDVI atingisse um valor maior que a razão de consistência, como se observar na segunda coluna da Tabela 4.

Tabela 4 - Pesos atribuídos aos critérios/fatores determinados na Análise Hierárquica (AHP).

\begin{tabular}{lcc}
\hline \multicolumn{1}{c}{ Critérios $^{(\mathbf{1})}$} & $\begin{array}{c}\text { Peso calculado } \\
\text { (AHP) }\end{array}$ & $\begin{array}{c}\text { Peso Recalculado } \\
\text { (AHP) }\end{array}$ \\
\hline NDVI & 0,0549 & 0,0864 \\
Uso do Solo & 0,6554 & 0,3741 \\
Fisiográfico & 0,2897 & 0,5395 \\
\hline
\end{tabular}

(1) Variáveis: NDVI, Uso do Solo e Aspectos Fisiográficos
Quando se substituiu a variável declividade pela variável fisiográfico e esta passou a ser a mais valorada, o resultado dos novos pesos foi alterado significativamente.

O mapa resultante (Figura 6) apresenta classes associadas às informações fisiográficas, destacando áreas mais vulneráveis aos movimentos de massa, segundo os pesos atribuídos para cada variável. Neste mapa são destacadas, na cor verde, as áreas de baixa suscetibilidade, seguidas das áreas amarelas de média suscetibilidade e áreas em vermelho de alta suscetibilidade a movimentos de massa na Sub-bacia hidrográfica do Rio Três Forquilhas, coincidindo com as ocorrências verificadas em campo.

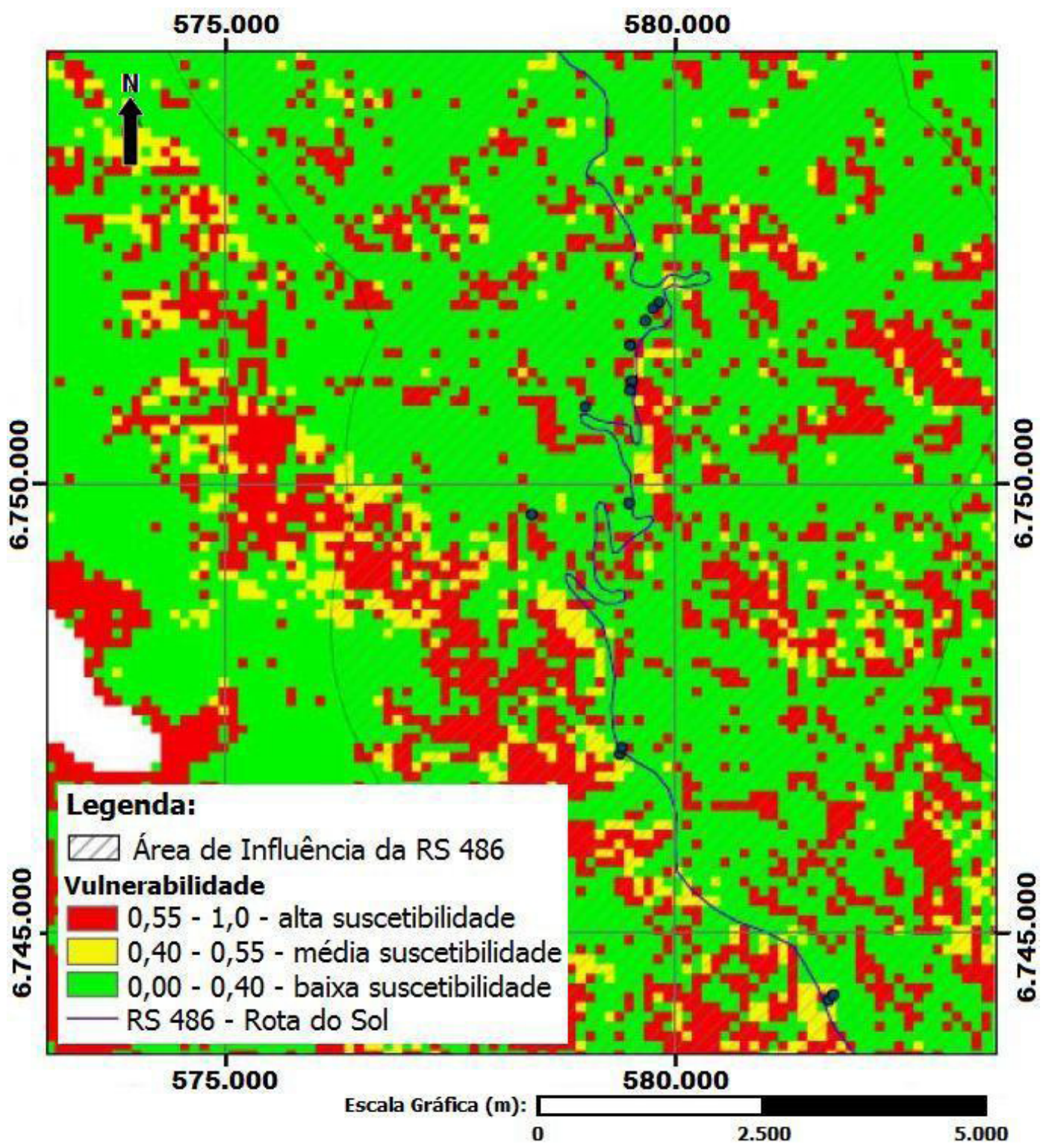

Figura 6. Determinação das áreas suscetíveis a movimentos de massa na Sub-bacia hidrográfica do Rio Três Forquilhas, RS. 


\section{Conclusões}

O uso da matriz pareada é de fácil aplicação quando se têm pré-determinados os pesos, critérios e variáveis envolvidos para a tomada de decisão. Quando somente a variável de aspectos fisiográficos é mais valorada, ocorre uma generalização de áreas de baixa vulnerabilidade. $\mathrm{O}$ produto gerado identifica prováveis áreas de ocorrência de movimentos de massa para a Sub-bacia hidrográfica do Rio Três Forquilhas e pode contribuir para o monitoramento e a prevenção de desastres naturais ou mistos, na região.

O emprego da matriz de consistência obteve resposta significativa e forte relação com os pontos de deslizamentos verificados em campo e localizados geograficamente com receptor GPS. Em ambos os levantamentos de campo, verificaram-se novos deslizamentos nos locais com registros anteriores, logo, recorrentes.

Sugere-se uma análise pontual das características do relevo das áreas de maior susceptibilidade a movimentos de massa, considerando também fatores propostos por alguns autores como comprimento de rampa, amplitude das vertentes, pluviosidade e unidades de relevo em grande escala.

\section{Referências}

ALBERTON, J. O. 2004. Manual - Ocupação de Encostas1991. IPT - Instituto De Pesquisas Tecnológicas. Disponível em: $<$ www.soniaa.arq.prof.ufsc.br/ soniaa/arq1206/2004/ josicler/ MarcioCunhaIPT_Manual1991.PDF>. Acesso em: 25 ago. 2007.

LISBOA, N. A. 1996. Fácies, estratificação hidrogeoquímica e seus controladores hidrogeológicos, em unidades hidrogeológicas do Sistema Aqüífero Serra Geral na Bacia do Paraná, Rio Grande do Sul. Tese de Doutoramento em Geociências, Instituto de Geociências, Universidade Federal do Rio Grande do Sul.

IBGE. Folha SH-22 Porto Alegre e parte das folhas SH-21 Uruguaiana e SI-22 Lagoa Mirim. Rio de Janeiro, 1986. 796 p. (Levantamento dos Recursos Naturais, 33).
CARVALHO, C. M.; ROEDEL, P. S. Análise de Suscetibilidade a escorregamentos nos entornos dos polidutos de Cubatão. 2. ed. São Paulo: Holos Environment, v. 4, 2004.

CHRISTOFOLETTI, A. Geomorfologia fluvial. São Paulo: Edgard Blücher, 1981. 313 p.

DIAS, R. A.; LISBOA, N.; VERDUM, R.; AREND, S.; POTTER, P. E. O Controle dos movimentos de massa e de seus depósitos pela estratigrafia vulcânica da formação Serra Geral na Escarpa do Planalto Meridional, Vale dos Três Forquilhas, RS. In. SIMPÓSIO SOBRE VULCANISMO E AMBIENTES ASSOCIADOS, 1., 1999, Gramado. Anais... Gramado: SBG, 1999.

ESRI. Manual Digital da ESRI para ArcGIS. Disponivel em: $<$ http://www.esri.com/software/arcgis/arcgisonline/index.html $>$. Acesso em: 10 maio 2007.

FEPAM. Fundação Estadual de Proteção Ambiental Henrique Luís Roessler. Programa de Gerenciamento Costeiro. Disponível em: <www.fepam.rs.gov.br>. Acesso em: 22 fev. 2004.

FERNANDES, N. F.; AMARAL, C. P. (2003). Movimentos de Massa: Uma Abordagem Geológico-Geomorfológico. In: GUERRA, A. J. T.; CUNHA, S. B. (orgs). Geomorfologia e Meio Ambiente. Editora Bertrand Brasil. Rio de Janeiro Cap.3, p 123-194.

GOMES, A. M. B. Aspectos da evolução geomorfológica da escarpa oriental do planalto meridional durante o quaternário. Porto Alegre: [s.n.], 1976.

NUMMER, A. V. Parâmetros geológicos-geotécnicos controladores dos movimentos de massa na Rota do Sol/RS486 - Itati. Porto Alegre: UFRGS, 2003.

ROSS, J. L. S. Geomorfologia: ambiente e planejamento. 2. ed. São Paulo: Contexto, 1991.

ROUSE, J. W., HAAS, R. H., SCHELL, J. A., DEERING, D. W. 1973. Monitoring vegetation systems in the Great Plaints with ETRS. In: Third ETRS Symposium, 1973. NASA SP353, Proceedings, Washington DC. p. 309-317.

SAATY, T. A scaling method for priorities in hierarchical structures. Psychology, v. 15, p. 234-281, 1977.

VARNES D. J., Slope movement types and processes. In: Schuster R. L. \& Krizek R. J. Ed., Landslides, analysis and control. Transportation Research Board Sp. Rep. No. 176, Nat. Acad. oi Sciences, p. 11-33, 1978.

Recebido em 28 de novembro de 2009 e aprovado em 13 de julho de 2010 
